\title{
Testing for the Effects and Consequences of Mid Paleogene Climate Change on Insect Herbivory
}

Torsten Wappler ${ }^{\mathbf{1}}$, Conrad C. Labandeira ${ }^{\mathbf{2}, \mathbf{3}}$, Jes Rust ${ }^{\mathbf{1}}$, Herbert Frankenhäuser ${ }^{\mathbf{4}}$, Volker Wilde ${ }^{5}$

1 Steinmann Institute, University of Bonn, 53115 Bonn, Germany; 2 Department of Paleobiology, National Museum of Natural History, Smithsonian Institution, Washington, DC 20013, USA; 3 Department of Entomology and BEES Program, University of Maryland, College Park, MD 20742, USA; 4 Mainz Natural History Museum / State Collection for Natural History of Rhineland-Palatine, Mainz, Germany; 5 Senckenberg Forschungsinstitut und Naturmuseum, Paläobotanik, Frankfurt am Main, Germany.

* Author for correspondence.

\section{ELECTRONIC SUPPLEMENTARY MATERIAL}

\section{FILE S1}

Dataset 1. Summary data for the Messel maar locality. The number of occurrences of each damage type (DT) was recorded. 


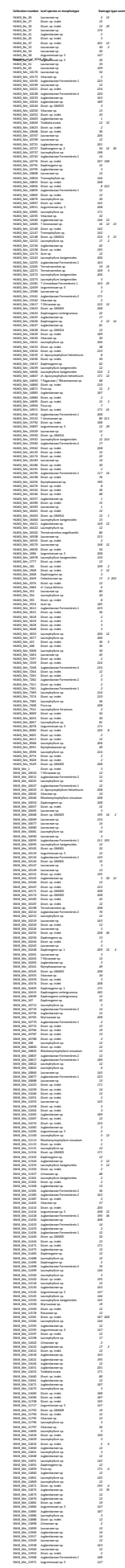




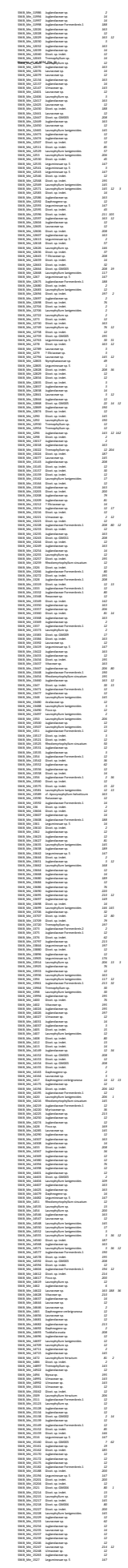




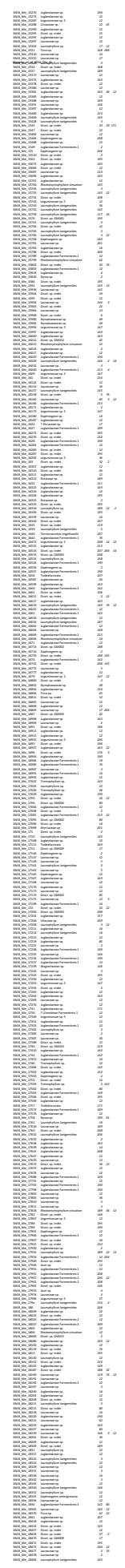






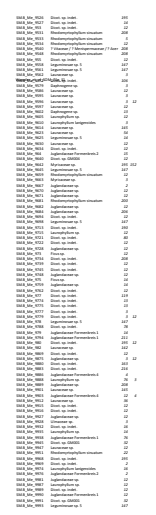




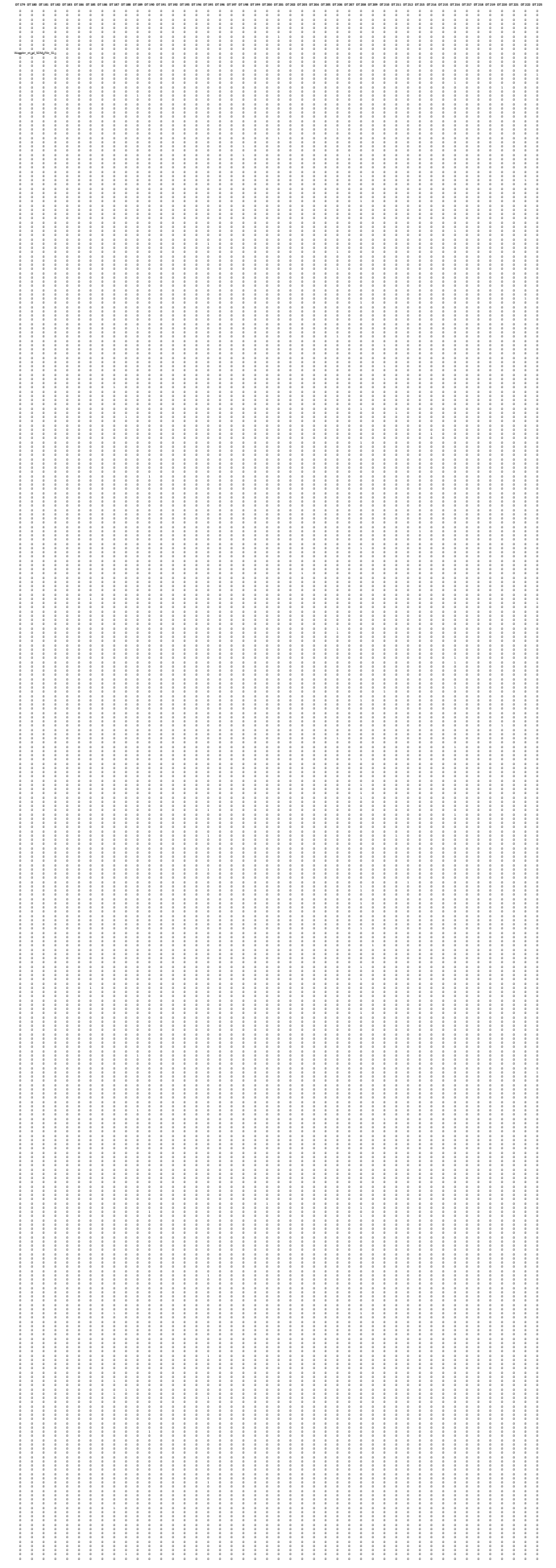




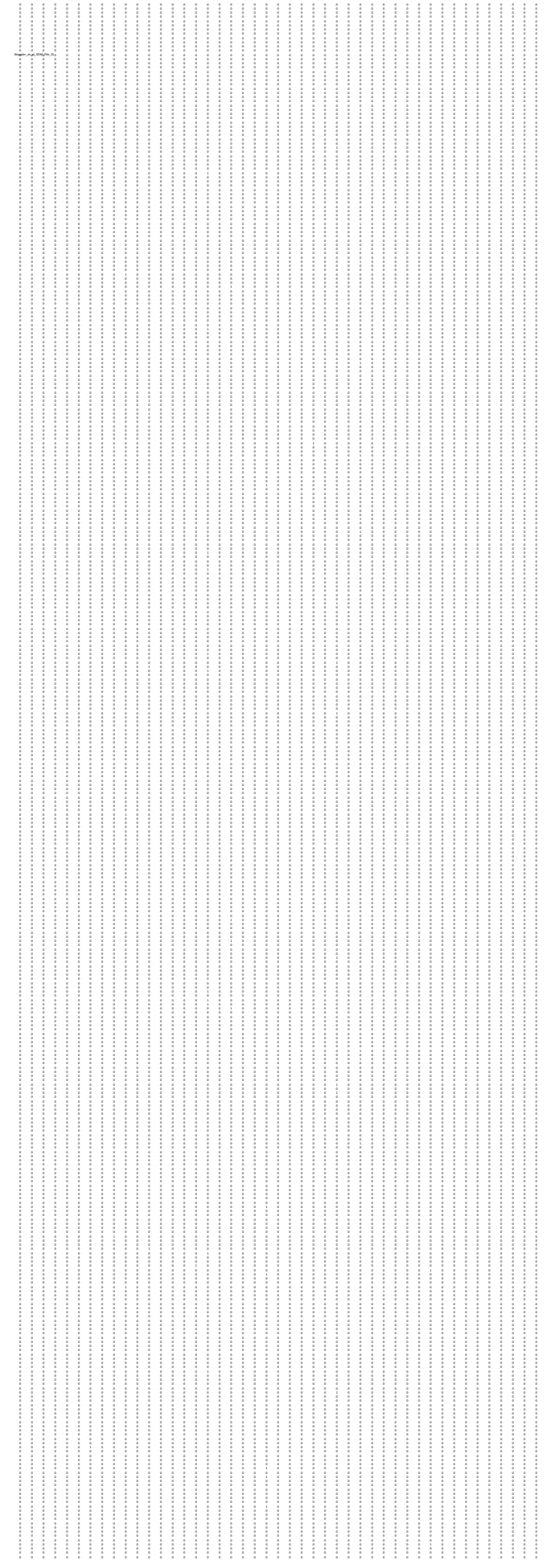




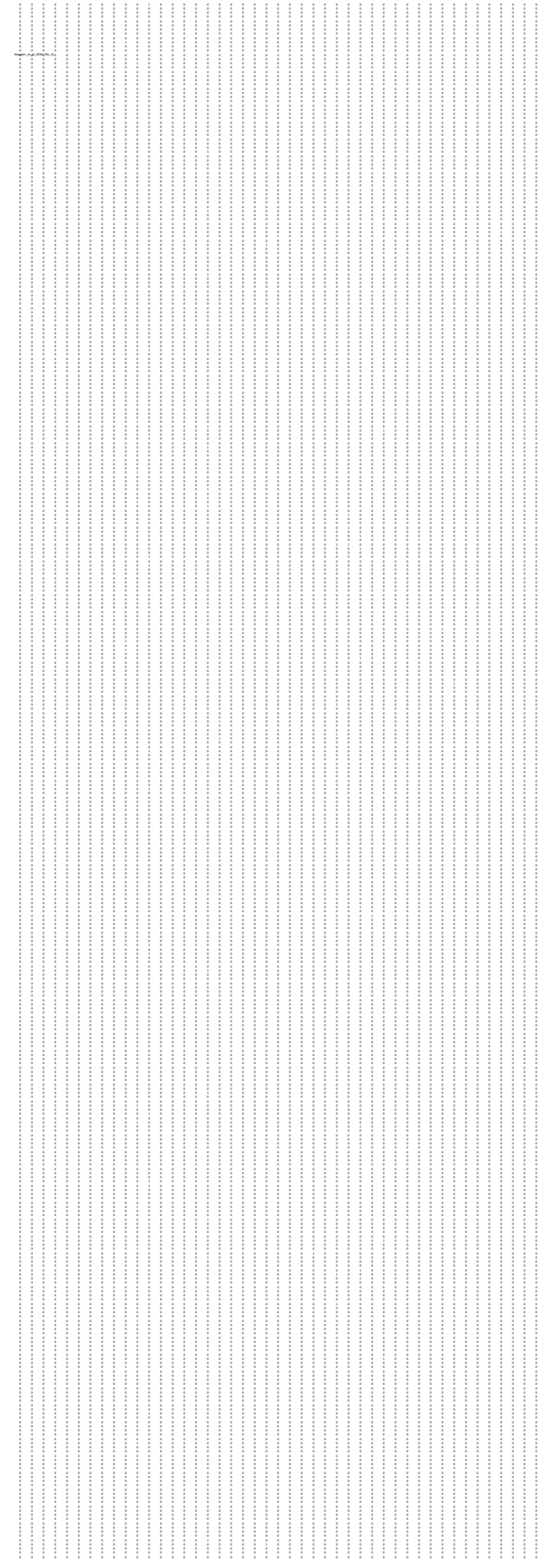




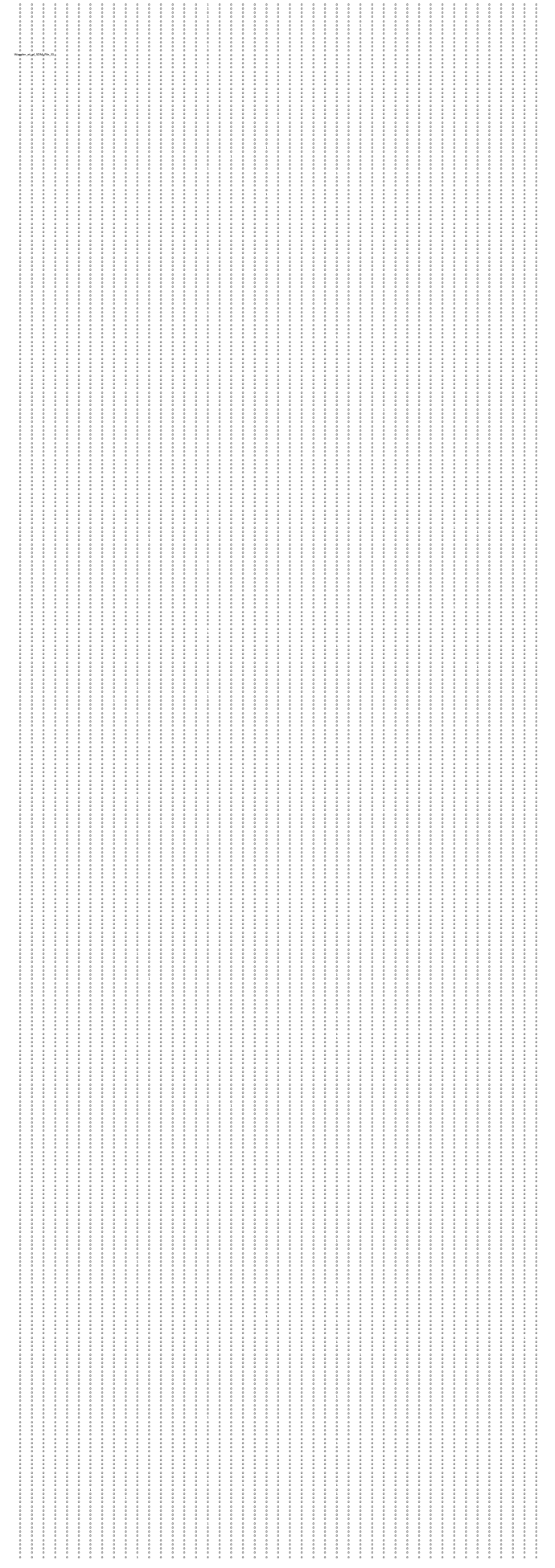




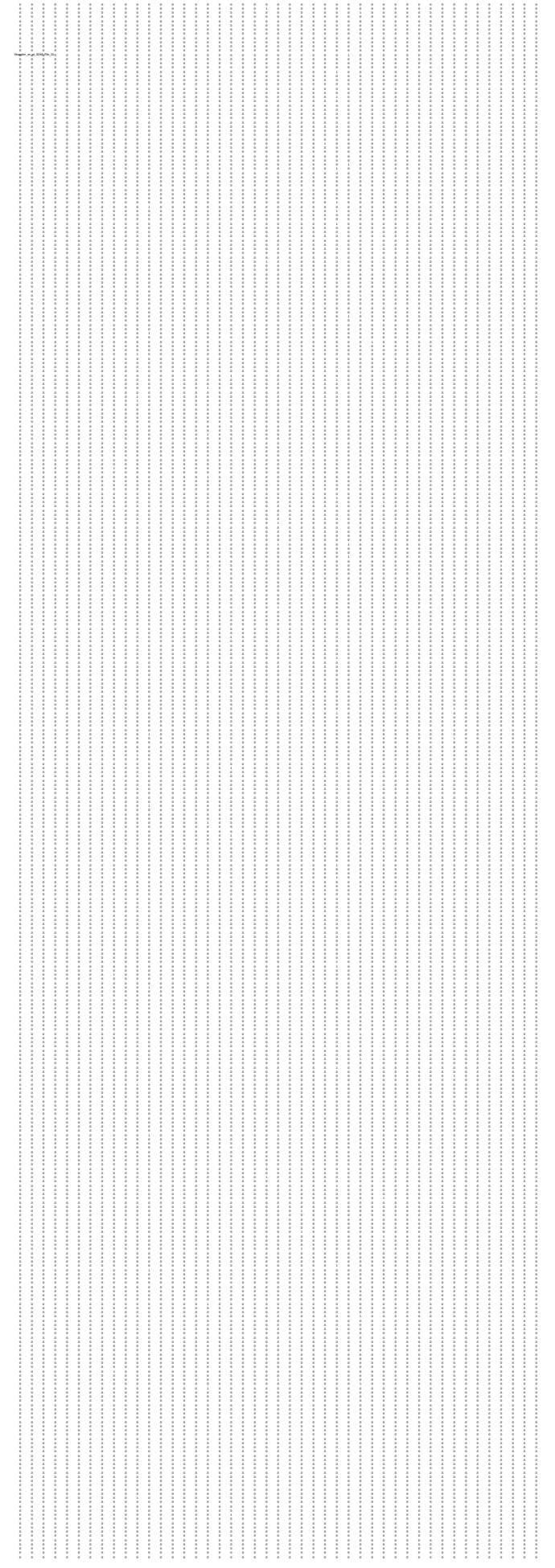


